\title{
Treatment adherence to disease-modifying antirheumatic drugs in Chinese patients with rheumatoid arthritis
}

This article was published in the following Dove Press journal:

Patient Preference and Adherence

4 May 2016

Number of times this article has been viewed

\author{
Yunfei Xia ${ }^{1, *}$ \\ Rulan Yin ${ }^{1,2, *}$ \\ Ting $\mathrm{Fu}^{1,2}$ \\ Lijuan Zhang ${ }^{1,2}$ \\ Qiuxiang Zhang ${ }^{1,2}$ \\ Genkai Guo' \\ Liren $\mathrm{Li}^{2}$ \\ Zhifeng Gu'
}

'Department of Rheumatology, Affiliated Hospital of Nantong University,

${ }^{2}$ School of Nursing, Nantong University, Nantong, People's Republic of China

*These authors contributed equally to this work
Correspondence: Liren $\mathrm{Li}$

School of Nursing, Nantong University,

19th Qixiu Road, 22600I Nantong,

People's Republic of China

Email larry017@I63.com

Zhifeng Gu

Department of Rheumatology, Affiliated Hospital of Nantong University, 20th Xisi Road, 22600I Nantong, People's Republic of China

Email guzhifeng@I26.com
Objective: Nonadherence in rheumatoid arthritis (RA) patients using disease-modifying antirheumatic drugs (DMARDs) may lead to joint damage and function loss. The aim of this cross-sectional study was to explore Chinese RA patients' adherence rates and investigate potential risk factors for nonadherence.

Methods: A total of 122 RA patients were recruited from the Affiliated Hospital of Nantong University from January 2014 to April 2015. Patients were asked to complete a set of standardized self-report questionnaires (Compliance Questionnaire on Rheumatology, Health Assessment Questionnaire, Short Form-36 questionnaire, 28-joint Disease Activity Score, Hospital Anxiety and Depression Scale, and Visual Analog Scale). Independent samples $t$-tests, chi-square analyses, and logistic regression modeling were used to analyze these data.

Results: Based on Compliance Questionnaire on Rheumatology, 38\% of the patients adhered to DMARDs. Adherence was associated with education, income, depression, and the total number of DMARDs. Other demographic and clinical characteristics were not associated with adherence. Logistic regression models identified income, depression, and the total number of DMARDs as predictors of medication nonadherence.

Conclusion: In this study, $62 \%$ of patients with RA were not adherent to their DMARD prescription. Education, income, depression, and the total number of DMARDs were associated with medication adherence, and income, depression, and the total number of DMARDs were independent predictors of medication adherence in patients with RA. These findings could help medical personnel develop helpful interventions to improve adherence in RA patients by paying more attention to the patients with these accompanying risk factors and, finally, improve RA patients' quality of life.

Keywords: rheumatoid arthritis, disease-modifying antirheumatic drugs, adherence

\section{Introduction}

Rheumatoid arthritis (RA) is a chronic, progressive, debilitating autoimmune disease, which is most prevalent in middle-aged and old women, with an incidence rate in the range of $0.32 \%-0.38 \%$. In the course of disease development, recurrent joint pain, swelling, and deformities, which seriously influence patients' quality of life, appear among partial patients. Over the last decade, great advances have been made in the treatment of RA with the development of new biologic therapies. ${ }^{1}$ Despite these advances, oral disease-modifying antirheumatic drugs (DMARDs), most commonly methotrexate, and others, such as leflunomide, hydroxychloroquine, and sulfasalazine, remain the cornerstone of therapy in RA and are invariably used as initial therapy. ${ }^{2}$ Since there is increasing evidence that earlier and more aggressive treatment of RA 
with nonbiologic and biologic DMARDs reduces symptoms of the condition and slows disease progression, ${ }^{3,4}$ it is crucial to ensure that patients take DMARDs regularly and correctly following the clinicians' prescription to maintain joint function to the fullest extent. ${ }^{5}$ However, adherence rate to medication in patients with RA is low, varying from $30 \%$ to $80 \% .^{6}$ A study from the USA, using the Medication Event Monitoring System, reported that only one fifth of patients with RA had an overall adherence to DMARDs. ${ }^{2}$ Another study from the Netherlands presented that $32 \%-40 \%$ of the patients did not adhere to their DMARD prescription. ${ }^{7}$ Previous studies have reported that DMARD nonadherence results in more disease activity/radiological damage, loss of function, and a lower quality of life. ${ }^{8-10}$ This indicates that it is very necessary to strengthen the study of medication adherence and its risk factors. Although previous studies in RA identified a variety of sociodemographic, psychological, and/or clinical variables related to adherence, none of these variables was consistently related in all studies. ${ }^{7,8,11-14}$ Additionally, to our knowledge, there are currently no data from mainland China.

The aims of this descriptive study were 1) to evaluate the extent of treatment adherence to DMARDs in Chinese patients with RA and 2) to explore demographic, clinical (drug use and biochemical criterion), and psychological (anxiety and depression) risk factors for nonadherence using a representative sample of RA patient population from Nantong, People's Republic of China.

\section{Patients and methods}

\section{Participants}

Patients who fulfilled the American College of Rheumatology (1987 or 2012) criteria for RA were recruited from the Affiliated Hospital of Nantong University from January 2014 to April 2015. A total of 129 patients with RA were constantly invited to participate in a single-center cross-sectional study and 122 (94.57\% of the patients) took part in and completed questionnaires in the end. All the patients have been told by the rheumatologist who prescribed the drugs the importance of adherence to DMARD therapy in controlling the disease. Patients were excluded if they were under 18-years-old, diagnosed with life-threatening disorders and severe mental disorders, or found without the use of prescribed DMARDs. All other patients were included, regardless of disease duration, seriousness of the condition, recent surgery, or comorbidity. This study was approved by the Ethics Committee of Affiliated Hospital of Nantong University, and the Clinical Trial Registration number for this study is 2014-387. Written informed consent was obtained from each participant.

\section{Methods}

Patients with RA were asked to complete a set of standardized self-report questionnaires (Compliance Questionnaire on Rheumatology [CQR], Health Assessment Questionnaire, Short Form-36 questionnaire, 28-joint Disease Activity Score [DAS28], Hospital Anxiety and Depression Scale, and Visual Analog Scale). The personal medication was gained by querying the electronic medical records combining with patients' self report. Results were totally gained by nurses blinded to study groupings and added to a computer database by two blinded research assistants who rechecked totals prior to entering the data.

\section{Demographics and clinical characteristics}

Demographic variables contain the following: age, sex, marital status, education attainment, occupation, monthly per capita income, type of medical insurance, family history, disease duration, comorbidity, hospitalization, tobacco use, and alcohol use. Clinical variables include the total number of DMARDs, which consist of biological and nonbiological DMARDs, total number of medicines, and non-steroidal anti-inflammatory drug (NSAID) use.

\section{Self-reported adherence}

Adherence was assessed using the CQR. The CQR is a 19-item, self-administered questionnaire, and was developed to correctly identify patients who were classified as "low" adherers (taking $<80 \%$ of their medication correctly). The questions were identified through focus groups and clinician's expert opinion of the likely hindrances to medication taking. The 4-point Likert answering scale ranges from "Definitely don't agree" (scored 1) to "Definitely agree" (scored 4); items 4, 8, 9, 11, 12, and 19 have to be reversely recoded $(4=1,3=2$, etc). Lower scores indicate lower levels of adherence. The CQR was validated against Medication Event Monitoring System and found to correctly identify $62 \%$ of low adherers without the extensive time and costs which are combined with "gold standard" medication monitoring techniques, such as pill counting or blood chemistry levels. Another advantage to the questionnaire is that the answers can indicate to us some social or cognitive reasons behind nonadherence. When used in conjunction with specialized psychosocial measures, this provides the potential for health care professionals to address problems exposed by the questionnaire as hindrances to taking medication..$^{5,15-17}$

\section{Health Assessment Questionnaire}

The Health Assessment Questionnaire, a total of 20 items, was used to rate activity limitation (range from 0 to 3 ), 
where $0=$ "without difficulty" and $3=$ "unable to do" in eight domains (dressing and grooming, arising, eating, walking, hygiene, reaching, gripping, and common daily activities), with higher scores indicating more disability. ${ }^{18}$

\section{Measure of the quality of life}

The general health status of each patient was measured using the Short Form-36 questionnaire, which measures eight multi-item dimensions: physical functioning (ten items); role limitations due to physical problems (four items); role limitations due to emotional problems (three items); social functioning (two items); mental health (five items); energy/ vitality (four items); body pain (two items); and general health perception (five items). For each dimension, the item scores were coded, summed, and transformed on a scale from 0 (worst possible health state measured by the questionnaire) to 100 (best possible health state). ${ }^{19}$

\section{Disease activity}

Disease activity was estimated with the valid and reliable DAS28, incorporating 28 swollen and tender joint counts, patient's assessment of disease activity (0-100 mm Visual Analog Scale, where $0=$ not active at all and $100=$ extremely active), erythrocyte sedimentation rate ( $\mathrm{mm} / \mathrm{hour}$ ), and C-reactive protein $(\mathrm{mg} / \mathrm{L})$. The questionnaire was also used to collect concurrent information about disease-related data and general health perception rated on visual analog scale. ${ }^{20}$

\section{Hospital Anxiety and Depression Scale}

The Hospital Anxiety and Depression Scale is designed to assess both anxiety and depression in outpatient populations. Each subscale includes seven items which are rated on a 4-point scale and scored from 0 to 3 with total scores therefore ranging from 0 to 21 for each subscale. Scores between 0 and 7 suggest "no case"; 8 to 10 represent a "possible case"; and 11 to 21 indicate a "probable case of anxiety/depression". These cutoff points have been validated against clinical interviews with sensitivity and specificity approximately 0.80 . Recent studies have reported good internal consistency for both anxiety (0.89) and depression $(0.86)$ subscales. $^{21,22}$

\section{Data analysis}

Descriptive statistics are provided using mean $( \pm$ standard deviation) or number (percentage) depending on parametric distribution of measured variables. Potential demographic, clinical, and psychological variables were screened using univariate tests of the group difference (adherent versus nonadherent according to the dichotomized (QR) at a lenient level of significance without correction for multiple testing (alpha $=0.05)$. We used chi-square tests to evaluate differences in proportions. Independent sample $t$-tests were used to evaluate differences in mean. Multivariate analysis was performed to explore how a number of variables might jointly affect adherence behavior. All social demography variables with a significant association with adherence by univariate tests were entered into a logistic regression model with the dichotomous adherence evaluated by the CQR as the dependent variable. Data were analyzed using SPSS (version 21.0).

\section{Results}

\section{Demographics and clinical characteristics}

Demographic, clinical, and psychological characteristics of the study population are described in Table 1. This study group reflects a normal RA population with $86 \%$ of the patients being female, a mean (standard deviation) age of 55.20 years (11.08 years), $91 \%$ being married, and with disease duration of 8.76 years ( 9.20 years). Approximately half of the patients' monthly per capita income was $<1,000$ yuan. The educational level was mostly medium to low. In all, $54 \%$ of the participants had secondary education, and only $11 \%$ were highly educated. Nine (7\%) patients were found with family history, $7 \%$ with tobacco use, and $18 \%$ without alcohol use. A total of 99 patients with RA had an experience of being in hospital before.

As shown in Table 1, the majority of participants used two to three types of DMARDs. Leflunomide was the most prescribed DMARD (72\%), followed by methotrexate (64\%), hydroxychloroquine (54\%), biologic drug $(9 \%)$, sulfasalazine (5\%), or other DMARDs. Moreover, $49 \%$ of the study population used glucocorticoid, $47 \%$ used NSAIDs, and 51\% used radix paeoniae alba. This study group also reflects a normal RA population with a mean DAS28 (standard deviation) of 3.80 (1.51), erythrocyte sedimentation rate of 28.27 (26.75), C-reactive protein of 16.61 (24.45), and $69 \%$ of the patients were depressed.

\section{Self-reported adherence}

Previous studies used CQR to assess the patients' adherence as a cutoff at $80 \% .{ }^{7,23}$ According to this, $38 \%$ of the patients were adherent. This means that $45(38 \%)$ patients were adherent with prescribed medicines; 77 (62\%) patients' compliance is not well, based on the CQR.

\section{Differences between adherent and nonadherent patients}

Previous studies reported that nonadherent patients had higher disease activity scores, increased radiographic damage, higher 
Table I Demographic, clinical, and psychological characteristics of the patients with RA $(n=122)$

\begin{tabular}{|c|c|}
\hline Characteristics & Descriptives \\
\hline Age (years) mean $\pm S D$ & $55.20 \pm 11.08$ \\
\hline Sex, female, n (\%) & $104(86)$ \\
\hline \multicolumn{2}{|l|}{ Marital status, n (\%) } \\
\hline Married & III (9I) \\
\hline Other marital status & II (9) \\
\hline \multicolumn{2}{|l|}{ Education level, n (\%) } \\
\hline Primary (0-6 years) & $43(35)$ \\
\hline Secondary (7-12 years) & $66(54)$ \\
\hline Higher ( $>12$ years) & $13(11)$ \\
\hline \multicolumn{2}{|l|}{ Employment, n (\%) } \\
\hline Employed & $79(65)$ \\
\hline Unemployed & $43(35)$ \\
\hline \multicolumn{2}{|l|}{ Monthly per capita income, n (\%) } \\
\hline$<1,000$ yuan & $60(49)$ \\
\hline $1,000-2,999$ yuan & $46(38)$ \\
\hline $3,000-5,000$ yuan & $12(10)$ \\
\hline$>5,000$ yuan & $4(3)$ \\
\hline \multicolumn{2}{|l|}{ Type of medical insurance, $n(\%)$} \\
\hline With basic medical insurance & $86(7 I)$ \\
\hline Self-pay, n (\%) & $30(25)$ \\
\hline Other, n (\%) & $6(5)$ \\
\hline Hospitalization, yes, n (\%) & $99(8 \mathrm{I})$ \\
\hline Tobacco use, yes, n (\%) & $9(7)$ \\
\hline Alcohol use, yes, n (\%) & $22(18)$ \\
\hline Family history, yes, n (\%) & $9(7)$ \\
\hline Disease duration, mean $\pm S D$ & $8.76 \pm 9.20$ \\
\hline Comorbid conditions, yes, $\mathrm{n}(\%)$ & $46(38)$ \\
\hline \multicolumn{2}{|l|}{ Total number of DMARDs, $\mathrm{n}(\%)$} \\
\hline One & $31(25)$ \\
\hline Two & $53(43)$ \\
\hline Three & $33(27)$ \\
\hline$>$ Three & $5(4)$ \\
\hline ESR (mm/hour), mean \pm SD & $28.27 \pm 26.75$ \\
\hline $\mathrm{CRP}(\mathrm{mg} / \mathrm{L})$, mean $\pm \mathrm{SD}$ & $16.61 \pm 24.45$ \\
\hline DAS28, mean \pm SD & $3.80 \pm I .5 I$ \\
\hline $\mathrm{HAQ}$, mean $\pm \mathrm{SD}$ & $0.46 \pm 0.63$ \\
\hline VAS global $(\mathrm{mm})$, mean \pm SD & $4.32 \pm 2.76$ \\
\hline VAS pain $(\mathrm{mm})$, mean \pm SD & $3.94 \pm 3.18$ \\
\hline HADS anxiety, n (\%) & $85(70)$ \\
\hline HADS depression, n (\%) & $84(69)$ \\
\hline \multicolumn{2}{|l|}{ Domains of SF-36, mean \pm SD } \\
\hline $\mathrm{PF}$ & $57.50 \pm 29.07$ \\
\hline RP & $21.31 \pm 36.46$ \\
\hline $\mathrm{BP}$ & $48.22 \pm 25.86$ \\
\hline $\mathrm{GH}$ & $42.34 \pm 21.17$ \\
\hline VT & $51.39 \pm 18.82$ \\
\hline SF & $61.17 \pm 27.07$ \\
\hline RE & $35.52 \pm 43.44$ \\
\hline $\mathrm{MH}$ & $61.21 \pm 18.39$ \\
\hline
\end{tabular}

Abbreviations: RA, rheumatoid arthritis; SD, standard deviation; DMARD, disease-modifying antirheumatic drug; ESR, erythrocyte sedimentation rate; CRP, C-reactive protein; DAS28, 28-joint Disease Activity Score; HAQ, health assessment questionnaire; VAS global, visual analog scale for general health; VAS pain, visual analog scale for pain; HADS, hospital anxiety and depression scale; SF-36, short form-36 questionnaire; PF, physical functioning; RP, role limitations due to physical problems; BP, body pain; GH, general health perception; VT, energy/vitality; SF, social functioning; RE, role limitations due to emotional problems; $\mathrm{MH}$, mental health. degree of depression, and worse mental health, with a trend toward lower function as well, compared with adherent patients. $^{2}$ The differences of demographic, clinical, and psychological characteristics between adherent and nonadherent patients are presented in Table 2. Education level, monthly per capita income, depression, and the total number of DMARDs were found to be associated with adherence. With regard to age, sex, marital status, employment, disease duration, type of medical insurance, comorbid condition, hospitalization, family history, drinking, and smoking, no statistically significant differences were found between the two groups $(P>0.05)$. Adherent and nonadherent patients did not differ in terms of DAS28 score, Visual Analog Scale, Health Assessment Questionnaire, erythrocyte sedimentation rate, C-reactive protein, anxiety, eight dimensions of Short Form-36, or the use of NSAID, hormone, and biological agent $(P>0.05)$.

\section{Logistic regression analysis for adherence}

We used logistic regression analysis to investigate predictors of medication nonadherence, as indicated in Table 3. We found that monthly per capita income (odds ratio $=2.515$; $P<0.01$ ), depression (odds ratio $=4.305 ; P<0.01$ ), and the total number of DMARDs (odds ratio $=1.843 ; P<0.05$ ) were the predictors of medication nonadherence.

\section{Discussion}

As we know, DMARDs can obviously reduce disease activity and joint damage in patients with $\mathrm{RA},{ }^{24}$ so it is necessary to ensure that patients take medications as prescribed by their health care providers regularly and correctly. The extent to which a patient takes medication as prescribed is termed as "adherence". ${ }^{25}$ Nonadherence has been found to be linked with poorer treatment outcomes, progression of disease symptoms, complications, increased health services utilization, and hospital admission. ${ }^{26-30}$ The most feasible way to identify nonadherence in clinical practice is selfreport measures. ${ }^{7}$ Currently, there is only one validated rheumatology-specific adherence questionnaire, CQR. ${ }^{25}$ Previous studies have evaluated adherence using CQR 80\% cutoff scores. ${ }^{7,23}$ In the present study, we reported that based on the CQR, 38\% of Chinese RA patients were adherent to DMARDs. The proportion of adherence is in accordance with previous studies from other countries and areas, which indicates that adherence rates to prescribed medicine regimes in people with RA varies from $30 \%$ to $80 \% .{ }^{6}$ To our knowledge, this study is the first to estimate medication adherence and explore its risk factors in patients with RA in mainland China using a self-reported questionnaire. 
Table 2 Differences between demographic, clinical, and psychological characteristics of adherent and nonadherent patients

\begin{tabular}{|c|c|c|c|}
\hline Characteristics & Adherent $n=45$ & Nonadherent $\mathrm{n}=77$ & $P$-value \\
\hline Age (years) mean $\pm S D$ & $55.31 \pm 13.24$ & $55.14 \pm 9.69$ & 0.941 \\
\hline Sex, female, n (\%) & $40(89)$ & $64(83)$ & 0.386 \\
\hline Marital status, n (\%) & & & 0.772 \\
\hline Married & $40(89)$ & $71(92)$ & \\
\hline Other marital status & $5(\mathrm{II})$ & $6(8)$ & \\
\hline Education level, n (\%) & & & $0.016 *$ \\
\hline Primary (0-6 years) & $22(49)$ & $21(27)$ & \\
\hline Secondary (7-12 years) & $20(44)$ & $46(60)$ & \\
\hline Higher (>12 years) & $3(7)$ & $10(13)$ & \\
\hline Employment, n (\%) & & & 0.218 \\
\hline Employed & $26(58)$ & $53(69)$ & \\
\hline Unemployed & $19(42)$ & $24(3 I)$ & \\
\hline Monthly per capita income, $\mathrm{n}$ (\%) & & & $0.03 I^{*}$ \\
\hline$<\mathrm{I}, 000$ yuan & $28(62)$ & $32(42)$ & \\
\hline $1,000-2,999$ yuan & $13(29)$ & $33(43)$ & \\
\hline $3,000-5,000$ yuan & $3(7)$ & $9(12)$ & \\
\hline$>5,000$ yuan & I (2) & $3(4)$ & \\
\hline Type of medical insurance, $\mathrm{n}(\%)$ & & & 0.981 \\
\hline With basic medical insurance & $32(7 \mathrm{I})$ & $54(70)$ & \\
\hline Self-pay & II (24) & $19(25)$ & \\
\hline Other & $2(4)$ & $4(5)$ & \\
\hline Hospitalization, yes, n (\%) & $36(80)$ & $63(82)$ & 0.804 \\
\hline Tobacco use, yes, n (\%) & $3(7)$ & $6(8)$ & 1.000 \\
\hline Alcohol use, yes, n (\%) & $6(13)$ & $16(2 \mid)$ & 0.302 \\
\hline Family history, yes, n (\%) & $5(I I . I)$ & $4(5)$ & 0.397 \\
\hline Disease duration, mean \pm SD & $8.64 \pm 9.17$ & $8.84 \pm 9.27$ & 0.734 \\
\hline Comorbid conditions, yes, n (\%) & $20(44)$ & $26(34)$ & 0.240 \\
\hline Total number of DMARDs, $\mathrm{n}(\%)$ & & & $0.032 *$ \\
\hline One & $18(40)$ & $13(17)$ & \\
\hline Two & $15(33)$ & $38(49)$ & \\
\hline Three & II (24) & $22(29)$ & \\
\hline$>$ Three & I (2) & $4(5)$ & \\
\hline ESR (mm/hour), mean \pm SD & $24.42 \pm 24.86$ & $30.52 \pm 27.70$ & 0.129 \\
\hline $\mathrm{CRP}(\mathrm{mg} / \mathrm{L})$, mean $\pm \mathrm{SD}$ & $17.74 \pm 29.00$ & $15.94 \pm 21.53$ & 0.947 \\
\hline DAS28, mean \pm SD & $3.73 \pm 1.55$ & $3.85 \pm 1.50$ & 0.673 \\
\hline $\mathrm{HAQ}$, mean $\pm \mathrm{SD}$ & $0.53 \pm 0.70$ & $0.42 \pm 0.58$ & 0.595 \\
\hline VAS global $(\mathrm{mm})$, mean \pm SD & $4.4 \mathrm{I} \pm 3.05$ & $4.27 \pm 2.59$ & 0.781 \\
\hline VAS pain $(\mathrm{mm})$, mean $\pm S D$ & $3.92 \pm 3.34$ & $3.95 \pm 3.11$ & 0.951 \\
\hline HADS anxiety, n (\%) & $29(64)$ & $56(73)$ & 0.337 \\
\hline HADS depression, n (\%) & $25(56)$ & $59(77)$ & $0.015^{*}$ \\
\hline \multicolumn{4}{|l|}{ Domains of SF-36, mean \pm SD } \\
\hline PF & $54.11 \pm 31.43$ & $59.48 \pm 27.62$ & 0.327 \\
\hline $\mathrm{RP}$ & $25.56 \pm 39.70$ & $18.83 \pm 34.45$ & 0.239 \\
\hline $\mathrm{BP}$ & $51.67 \pm 26.54$ & $46.2 I \pm 25.4 I$ & 0.262 \\
\hline $\mathrm{GH}$ & $42.53 \pm 25.01$ & $42.23 \pm 18.75$ & 0.945 \\
\hline VT & $53.33 \pm 23.33$ & $50.26 \pm 15.66$ & 0.434 \\
\hline SF & $62.50 \pm 31.19$ & $60.39 \pm 24.54$ & 0.680 \\
\hline RE & $37.78 \pm 46.38$ & $34.20 \pm 41.88$ & 0.729 \\
\hline $\mathrm{MH}$ & $58.58 \pm 23.30$ & $62.75 \pm 14.76$ & 0.283 \\
\hline
\end{tabular}

Notes: $* P<0.05$. Adherence, measured with the Compliance Questionnaire on Rheumatology, is expressed as dichotomous ( $<80 \%$ or $\geq 80 \%$ adherence) variable.

Abbreviations: SD, standard deviation; DMARD, disease-modifying antirheumatic drug; ESR, erythrocyte sedimentation rate; CRP, C-reactive protein; DAS28, 28-Joint Disease Activity Score; HAQ, health assessment questionnaire; VAS global, visual analog scale for general health; VAS pain, visual analog scale for pain; HADS, hospital anxiety and depression scale; SF-36, short form-36 questionnaire; PF, physical functioning; RP, role limitations due to physical problems; BP, body pain; GH, general health perception; VT, energy/vitality; SF, social functioning; RE, role limitations due to emotional problems; MH, mental health. 
Table 3 Logistic regression analysis of demographic, medical, and psychological characteristics in relation to adherence

\begin{tabular}{lllllll}
\hline & Adherence & Beta & Standard error & P-value & Exp (B) & (95\% Cl) \\
\hline Step I & Education level & 0.510 & 0.390 & 0.191 & 1.665 & $0.776,3.573$ \\
& Monthly per capita income & 0.693 & 0.370 & 0.061 & 1.999 & $0.968,4.128$ \\
& HADS depression & 1.356 & 0.484 & 0.005 & 3.882 & $1.502,10.031$ \\
& Total number of DMARDs & 0.657 & 0.273 & 0.016 & 1.929 & $1.130,3.295$ \\
Step 2 & Monthly per capita income & 0.922 & 0.331 & $0.005 * *$ & 2.515 & $1.315,4.812$ \\
& HADS depression & 1.460 & 0.477 & $0.002^{* *}$ & 4.305 & $1.689,10.973$ \\
& Total number of DMARDs & 0.611 & 0.266 & $0.022^{*}$ & 1.843 & $1.094,3.104$ \\
\hline
\end{tabular}

Notes: $* P<0.05, * * P<0.01$.

Abbreviations: $\mathrm{Cl}$, confidence interval; HADS, hospital anxiety and depression scale; DMARD, disease-modifying antirheumatic drug.

Previous studies have reported that sex, age, disease duration, and education level were associated with medication adherence, and disease activity and side effects were not related to medication adherence. ${ }^{12,14,23,31}$ Chrzanowska et $\mathrm{l}^{32}$ reported that level of education did not significantly influence medication adherence. Lorish et $\mathrm{al}^{33}$ found that financial status was not associated with adherence. In the present study, our group found that medication adherence had an obviously positive correlation with education level and monthly per capita income. One possible explanation for the different results is the existence of cultural diversity between Chinese and Western population.

There is an increasing evidence that depression frequently occurs in RA. ${ }^{34}$ While many studies showed the association between depression and adherence in other diseases, fewer studies have been carried out in patients with RA. Julian et a ${ }^{35}$ reported that patients with both rheumatologic diseases and depression were less likely to be adherent with their medications. We also found that depression had a significantly negative impact on medication adherence, which is similar to previous studies from other countries. ${ }^{36-38}$ This may be due to the fact that RA is currently incurable and needs continuous therapy. This finding indicates the importance of carrying out patient education for RA patients with depression so as to improve their adherence to medication.

As reported by Kristensen et al, ${ }^{39}$ treating patients with more types of DMARD usage history may lead to premature treatment termination. Salt and Frazier ${ }^{40}$ reported that total number of prescriptions was the independent predictor of medication adherence. In the current study, most patients (70\%) took two to three types of DMARDs. We found that the number of DMARDs had a positive correlation with adherence in most patients, but more than three types would have a negative effect on patients' adherence.

To investigate predictors of medication nonadherence, we used logistic regression analysis. We found that monthly per capita income and depression had a significant effect on medication nonadherence. Interestingly, we also found that the total number of DMARDs played an important role in medication nonadherence. To our knowledge, it is the first time the potential risk factors of medication adherence in Chinese patients with RA have been explored.

However, this study has several limitations. First, all patients involved in this investigation were only from one center. Second, the measurement to identify adherence was subjective, which may result in a possible overestimation or misclassification of adherence due to the absence of an objective "gold standard" for adherence. Third, a proportion of patients in our study were people with terminal RA combined with interstitial pneumonia, and the doctors took no account of the RA patients' fertility for the basic national condition of the People's Republic of China, so the current study reported leflunomide being the most prescribed DMARD, followed by methotrexate, the generally accepted anchor drug. Other limitations of the study also exist, such as problems in causal inference due to a cross-sectional design.

\section{Conclusion}

We have first reported that $38 \%$ of Chinese patients with RA were adherent to DMARDs. Education level, monthly per capita income, depression, and total number of DMARDs were significantly correlated with adherence. In mainland China, the results indicated that rheumatologists and nurses should pay attention to RA patients' medication adherence, especially those with a low degree of education, low monthly per capita income, being depressive, and/or taking more types of DMARDs by patient education or some other ways so as to improve patients' prognosis and, finally, improve RA patients' quality of life.

\section{Acknowledgments}

We want to thank all the investigators who participated in this study. We acknowledge Yan Sang, Biyu Shen, Haixia Cao, Yan Meng, Jie Qian, Fengyan Zhou, Zhanyun Da, and Xinhang Zhu for their assistance in this study. This research 
was supported by grants from the Cultivative Distinguished Young Scholars Project of Nantong University (2nd); the Innovation Talent Project of Nantong University (4th); the Collaborative Innovation Program of Affiliated Hospital of Nantong University; the 2015 Graduate Innovation Project of Nantong University (YKC15075); and College graduate research and innovation of Jiangsu Province (KYZZ15-0353).

\section{Author contributions}

All authors contributed toward data analysis, drafting and critically revising the paper and agree to be accountable for all aspects of the work.

\section{Disclosure}

The authors report no conflicts of interest in this work.

\section{References}

1. Klarenbeek NB, Allaart CF, Kerstens PJ, Huizinga TW, Dijkmans BA. The BeSt story: on strategy trials in rheumatoid arthritis. Curr Opin Rheumatol. 2009;21(3):291-298.

2. Waimann CA, Marengo MF, de Achaval S, et al. Electronic monitoring of oral therapies in ethnically diverse and economically disadvantaged patients with rheumatoid arthritis: consequences of low adherence. Arthritis Rheum. 2013;65(6):1421-1429.

3. Grigor C, Capell H, Stirling A, et al. Effect of a treatment strategy of tight control for rheumatoid arthritis (the TICORA study): a single-blind randomised controlled trial. Lancet. 2004;364(9430):263-269.

4. Verstappen SM, Jacobs JW, van der Veen MJ, et al; Utrecht Rheumatoid Arthritis Cohort Study Group. Intensive treatment with methotrexate in early rheumatoid arthritis: aiming for remission. Computer Assisted Management in Early Rheumatoid Arthritis (CAMERA, an open-label strategy trial). Ann Rheum Dis. 2007;66(11):1443-1449.

5. Hughes LD, Done J, Young A. A 5 item version of the Compliance Questionnaire for Rheumatology (CQR5) successfully identifies low adherence to DMARDs. BMC Musculoskelet Disord. 2013;14:286.

6. van den Bemt BJ, Zwikker HE, van den Ende $\mathrm{CH}$. Medication adherence in patients with rheumatoid arthritis: a critical appraisal of the existing literature. Expert Rev Clin Immunol. 2012;8(4):337-351.

7. van den Bemt BJ, van den Hoogen FH, Benraad B, Hekster YA, van Riel PL, van Lankveld W. Adherence rates and associations with nonadherence in patients with rheumatoid arthritis using disease modifying antirheumatic drugs. $J$ Rheumatol. 2009;36(10):2164-2170.

8. Contreras-Yáñez I, Ponce De León S, Cabiedes J, Rull-Gabayet M, Pascual-Ramos V. Inadequate therapy behavior is associated to disease flares in patients with rheumatoid arthritis who have achieved remission with disease-modifying antirheumatic drugs. Am JMed Sci. 2010;340(4): 282-290.

9. van den Bemt BJF. Optimizing Pharmacotherapy in Patients with Rheumatoid Arthritis: An Individualized Approach. The Netherlands: Radboud University Nijmegen; 2009.

10. Viller F, Guillemin F, Briancon S, Moum T, Suurmeijer T, van den Heuvel W. Compliance to drug treatment of patients with rheumatoid arthritis: a 3 year longitudinal study. J Rheumatol. 1999;26(10): 2114-2122.

11. Borah BJ, Huang X, Zarotsky V, Globe D. Trends in RA patients' adherence to subcutaneous anti-TNF therapies and costs. Curr Med Res Opin. 2009;25(6):1365-1377.

12. Curkendall S, Patel V, Gleeson M, Campbell RS, Zagari M, Dubois R. Compliance with biologic therapies for rheumatoid arthritis: do patient out-of-pocket payments matter? Arthritis Rheum. 2008;59(10): 1519-1526.
13. Tuncay R, Eksioglu E, Cakir B, Gurcay E, Cakci A. Factors affecting drug treatment compliance in patients with rheumatoid arthritis. Rheumatol Int. 2007;27(8):743-746.

14. Garcia-Gonzalez A, Richardson M, Garcia Popa-Lisseanu M, et al. Treatment adherence in patients with rheumatoid arthritis and systemic lupus erythematosus. Clin Rheumatol. 2008;27(7):883-889.

15. de Klerk E, van der Heijde D, Landewe R, van der Tempel H, van der Linden S. The compliance-questionnaire-rheumatology compared with electronic medication event monitoring: a validation study. J Rheumatol. 2003;30(11):2469-2475.

16. de Klerk E, van der Heijde D, van der Tempel H, van der Linden S. Development of a questionnaire to investigate patient compliance with antirheumatic drug therapy. J Rheumatol. 1999;26(12):2635-2641.

17. Zwikker HE, van Dulmen S, den Broeder AA, van den Bemt BJ, van den Ende CH. Perceived need to take medication is associated with medication non-adherence in patients with rheumatoid arthritis. Patient Prefer Adherence. 2014;8:1635-1645.

18. Bruce B, Fries JF. The Stanford Health Assessment Questionnaire: dimensions and practical applications. Health Qual Life Outcomes. 2003;1:20.

19. Shen B, Feng G, Tang W, et al. The quality of life in Chinese patients with systemic lupus erythematosus is associated with disease activity and psychiatric disorders: a path analysis. Clin Exp Rheumatol. 2014;32(1): 101-107.

20. Prevoo ML, van Riel PL, van 't Hof MA, et al. Validity and reliability of joint indices. A longitudinal study in patients with recent onset rheumatoid arthritis. Br J Rheumatol. 1993;32(7):589-594.

21. Zigmond AS, Snaith RP. The hospital anxiety and depression scale. Acta Psychiatr Scand. 1983;67(6):361-370.

22. Olssøn I, Mykletun A, Dahl AA. The Hospital Anxiety and Depression Rating Scale: a cross-sectional study of psychometrics and case finding abilities in general practice. BMC Psychiatry. 2005;5:46.

23. Rauscher V, Englbrecht M, van der Heijde D, Schett G, Hueber AJ. High degree of nonadherence to disease-modifying antirheumatic drugs in patients with rheumatoid arthritis. $J$ Rheumatol. 2015;42(3): 386-390.

24. Park DC, Hertzog C, Leventhal H, et al. Medication adherence in rheumatoid arthritis patients: older is wiser. J Am Geriatr Soc. 1999;47(2): $172-183$.

25. Treharne GJ, Lyons AC, Hale ED, Douglas KMJ, Kitas GD. 'Compliance' is futile but is 'concordance' between rheumatology patients and health professionals attainable? Rheumatology (Oxford). 2006;45(1): $1-5$.

26. DiMatteo MR, Giordani PJ, Lepper HS, Croghan TW. Patient adherence and medical treatment outcomes: a meta-analysis. Med Care. 2002;40(9): 794-811.

27. Schiff GD, Fung S, Speroff T, McNutt RA. Decompensated heart failure: symptoms, patterns of onset, and contributing factors. Am J Med. 2003;114(8):625-630.

28. McDonnell PJ, Jacobs MR. Hospital admissions resulting from preventable adverse drug reactions. Ann Pharmacother. 2002;36(9): 1331-1336.

29. Jha AK, Aubert RE, Yao J, Teagarden JR, Epstein RS. Greater adherence to diabetes drugs is linked to less hospital use and could save nearly $\$ 5$ billion annually. Health Aff (Millwood). 2012;31(8):1836-1846.

30. Sokol MC, McGuigan KA, Verbrugge RR, Epstein RS. Impact of medication adherence on hospitalization risk and healthcare cost. Med Care. 2005;43(6):521-530.

31. Bliddal H, Eriksen SA, Christensen R, et al. Adherence to methotrexate in rheumatoid arthritis: a Danish nationwide cohort study. Arthritis. 2015.

32. Chrzanowska A, Batko B, Hajdyła-Banaś I, Banaś T, Krezelok M, Ludwin A. Adherence to disease-modifying antirheumatic drugs in patients with rheumatoid arthritis. Przegl Lek. 2014;71(4):199-203.

33. Lorish CD, Richards B, Brown S. Missed medication doses in rheumatic arthritis patients: intentional and unintentional reasons. Arthritis Care Res. 1989;2(1):3-9. 
34. Matcham F, Rayner L, Steer S, Hotopf M. The prevalence of depression in rheumatoid arthritis: a systematic review and meta-analysis. Rheumatology (Oxford). 2013;52(12):2136-2148.

35. Julian LJ, Yelin E, Yazdany J, et al. Depression, medication adherence, and service utilization in systemic lupus erythematosus. Arthritis Rheum. 2009;61(2):240-246.

36. Santiago T, Geenen R, Jacobs JW, Da Silva JA. Psychological factors associated with response to treatment in rheumatoid arthritis. Curr Pharm Des. 2015;21(2):257-269.

37. Cabrera-Marroquín R, Contreras-Yáñez I, Alcocer-Castillejos N, Pascual-Ramos V. Major depressive episodes are associated with poor concordance with therapy in rheumatoid arthritis patients: the impact on disease outcomes. Clin Exp Rheumatol. 2014;32(6):904-913.
38. DiMatteo MR, Lepper HS, Croghan TW. Depression is a risk factor for noncompliance with medical treatment: meta-analysis of the effects of anxiety and depression on patient adherence. Arch Intern Med. 2000; 160(14):2101-2107.

39. Kristensen LE, Saxne T, Nilsson JA, Geborek P. Impact of concomitant DMARD therapy on adherence to treatment with etanercept and infliximab in rheumatoid arthritis. Results from a six-year observational study in southern Sweden. Arthritis Res Ther. 2006;8(6):R174.

40. Salt E, Frazier SK. Predictors of medication adherence in patients with rheumatoid arthritis. Drug Dev Res. 2011;72(8):756-763.

\section{Publish your work in this journal}

Patient Preference and Adherence is an international, peer-reviewed, open access journal that focuses on the growing importance of patient preference and adherence throughout the therapeutic continuum. Patient satisfaction, acceptability, quality of life, compliance, persistence and their role in developing new therapeutic modalities and compounds to optimize clinical outcomes for existing disease states are major areas of interest for the journal. This journal has been accepted for indexing on PubMed Central. The manuscript management system is completely online and includes a very quick and fair peer-review system, which is all easy to use. Visit http://www dovepress.com/testimonials.php to read real quotes from published authors.

Submit your manuscript here: http://www.dovepress.com/patient-preference-and-adherence-journal 